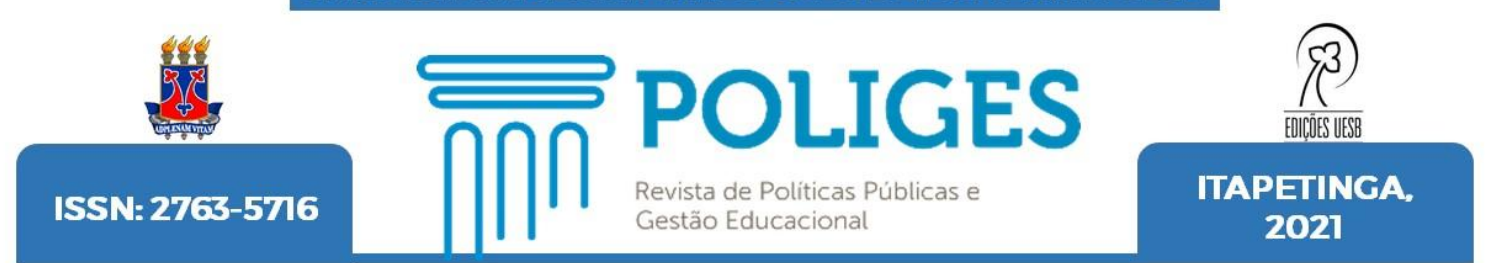

\title{
DIREITO À EDUCAÇÃO: A INVISIBILIDADE DA EJA NA BNCC
}

\author{
RIGHT TO EDUCATION: THE INVISIBILITY OF EJA IN THE BNCC
}

\author{
DERECHO A LA EDUCACIÓN: LA INVISIBILIDAD DE LA EJA EN EL BNCC
}

Daniela Lopes Oliveira Dourado orcid https://orcid.org/0000-0003-4642-0919 Universidade do Estado da Bahia (UNEB) - Brasil

\author{
Ana Karine Loula Torres Rocha \\ https://orcid.org/0000-0002-1915-3045 \\ Universidade do Estado da Bahia (UNEB) - Brasil \\ Cinara Barbosa de Oliveira Morais \\ https://orcid.org/0000-0002-9674-8616 \\ Universidade do Estado da Bahia (UNEB) - Brasil \\ Maria de Fátima Sudré Andrade Bastos \\ https://orcid.org/0000-0002-7378-20109 \\ Universidade do Estado da Bahia (UNEB) - Brasil
}

DOI: $10.22481 /$ poliges.v2i1.8489

Resumo: $O$ artigo tem como objetivo discutir contradições e tensões provocadas pelo questionamento sobre qual espaço a Educação de Jovens e Adultos tem assumido na Base Nacional Comum Curricular (BNCC). Para fomentar a discussão procurou-se na pesquisa documental a sustentação de análise das informações pelos documentos oficiais primários: Constituição de 1988, a LDBN/96, o PNE e a BNCC. Por meio de um olhar qualitativo buscou-se interpretar o objeto de investigação num movimento de reflexão para compreender o fenômeno que inspirou a pesquisa. A invisibilidade da EJA na BNCC revela o silêncio e a negação da modalidade nas políticas públicas da educação no Brasil no atual cenário. Refletir sobre a temática exige o desafio à luta. Um imperativo para os novos rumos da educação de Jovens e Adultos.

Palavras Chave: BNCC. Modalidade EJA. Políticas Públicas

Abstract: The article aims to discuss contradictions and tensions caused by the questioning about which space the Education of Youth and Adults has assumed in the Common National Curriculum Base (BNCC). To foster the discussion, it was sought in the documentary research the support of analysis of information by the primary official documents: 1988 Constitution, LDBN/96, PNE and BNCC. Through a qualitative look, we seek to interpret the 
object of investigation in a movement of reflection to understand the phenomenon that inspired the research. The invisibility of the EJA in the BNCC reveals the silence and denial of the modality in public policies of education in Brazil in the current scenario. Reflecting on the theme requires the challenge to the struggle. An imperative for the new directions of youth and adult education.

Keywords: BNCC. EJA. Public Policy

Resumen: El artículo tiene como objetivo discutir las contradicciones y tensiones provocadas por el cuestionamiento del espacio que ha tomado la Educación de Jóvenes y Adultos en la Base Curricular Común Nacional (BNCC). Para fomentar la discusión, se espera que la investigación documental apoye el análisis de la información de los principales documentos oficiales: Constitución de 1988, LDBN / 96, PNE y BNCC. A través de una mirada cualitativa, buscamos interpretar el objeto de investigación en un movimiento de reflexión para comprender el fenómeno que inspiró una investigación. La invisibilidad de EJA en el BNCC revela el silencio y la negación de la modalidad en las políticas públicas de educación en Brasil en el escenario actual. Reflexionar sobre el tema requiere un desafío a la lucha. Un imperativo para las nuevas direcciones de la educación de jóvenes y adultos.

Palabras clave: BNCC. Modo EJA. Políticas Públicas

\section{Introdução}

Historicamente, a educação de jovens e adultos (EJA), foi marcada por omissões em políticas públicas que por consequência não garantiam os direitos dos seus sujeitos, estes tiveram ao longo da vida o acesso à educação escolar negado por diversos motivos de ordem social e política. O reconhecimento da EJA como modalidade da educação básica é uma conquista muito recente, que culminou com a promulgação da Nova Lei de Diretrizes e Bases da Educação Nacional (LDB n 9694/96) já no final do século passado. A partir deste avanço, não se pode afirmar que a EJA conseguiu manter no cenário educacional, a progressão necessária para consolidar as políticas conquistadas, principalmente na atualidade, onde tem-se a percepção da ausência na Base Nacional Comum Curricular (BNCC).

A alta expressão do analfabetismo, a subescolarização e a imprevisibilidade de jovens e adultos, ainda é uma realidade perversa no cenário educacional brasileiro, por isso, torna-se contraditória a apresentação de perspectivas de desenvolvimento em qualquer área. Visto que, no decorrer dos tempos/espaços a EJA demarca em cada pegada do seu caminho, trajetórias de lutas pela educação como direito, daqueles e daquelas que, historicamente estiveram sempre à margem 
silenciados e invisibilizados pelas políticas públicas de educação do país. Diante da realidade da BNCC, demonstra-se a negligência diante da gestão da educação nacional.

Essas contradições e tensões, provocam o questionamento sobre qual espaço a educação de jovens e adultos tem assumido na Base Nacional Comum Curricular? Onde está a garantia de uma educação para e na diversidade com a perspectiva de integração, a qual inclui a modalidade EJA dentro da BNCC? Para essa discussão, faz-se necessário caminhar no tão sonhado projeto de educação brasileira, luta visionária dos Pioneiros da Educação conquistada na Constituição de 1988: a universalização da educação gratuita, como direito.

Entretanto, é preciso apresentar os avanços da EJA no cenário da década de 1990 como representação da luta pela educação de jovens e adultos no país, legitimada nos documentos oficiais e na construção de uma política pública da educação, que apesar da supressão neste momento na principal política pública orientadora da educação básica nacional, a BNCC, é fundamental retomar a caminhada que configurou com êxito estratégias de intervenção da gestão democrática e participativa, através de mecanismos de monitoria e avaliação social no Plano Nacional de Educação (PNE, 2014-2024), para legitimar a educação num plano de transformação e desenvolvimento nacional, ele representa um decênio de políticas de intervenção de gestão na educação brasileira.

No PNE a EJA está apresentada na Meta 9, a qual direciona a atuação da gestão pública com um plano de ação com estratégias de intervenção. A criação do PNE, na Lei $n^{\circ}$ 13.005/2014, mobilizou a participação das entidades, das universidades por meio de grupos de pesquisa, de fóruns e da representação da sociedade civil, em cada esfera da gestão pública.

Tencionar o silêncio no caminho da educação de jovens e adultos no atual cenário do século XXI, demarca ainda, um contínuo de intervenções sociais por meio de conferências para a construção do PNE, como as lutas históricas para enfrentar as desigualdades humanas e sociais, características desta modalidade. Visto que, já é entendido, que investimentos na EJA representam não apenas, enfrentamento dos grandes índices de analfabetismo e baixa escolarização da população jovem e adulta, inclui-se transformações com intervenção do Estado, para 
os grandes desafios da nação brasileira, pois além do acesso a escolarização, tem-se desenvolvimento humano, sociocultural e político, que representam melhores condições de vida, inclusão social e que se expande também à família dos jovens e adultos estudantes.

Dialogar sobre a preterição imposta pela BNCC quanto a EJA, é fundamental para consciência do que tudo isso implica e quais contextos podem ser previstos a partir desta realidade, a exemplo que, tal ausência imprime a negação de direito, e cria-se um movimento contrário as lutas e conquistas firmadas na Constituição Brasileira e na LDB/96, o que legitima a retirada da EJA do foco da educação básica e a coloca mais uma vez numa condição histórica de retrocesso, às margens periféricas do caminho.

Esses questionamentos mobilizaram a escrita desse artigo, que tenciona sobre a ausência da EJA na base curricular implantada na educação brasileira e provoca reflexões sobre as consequências desta política pública pra esta modalidade e demarca historicamente um contínuo de lutas, a partir da década de 90, quando a LDB ( $n^{\circ}$ 9394/ 96) determina seu status enquanto modalidade de Educação, reconhecida com o cumprimento da Constituição de 1988, Art. 205 ao concretizar a "educação como direito de todos[...]", revelando que não existe o tempo certo para acesso à educação escolar, qualquer pessoa poderá estudar em qualquer idade, um precedente histórico para homens e mulheres, que tiveram seus percursos educativos interrompidos e ou negados ao longo da educação no Brasil.

Nos aportes da pesquisa documental se definiu o caminho para a construção das discussões desse trabalho, que traz um enfoque qualitativo para a descrição interpretativa das informações sobre o fenômeno. Em Gil (2006), pesquisa documental tem sua validade em documentos. Destarte, as discussões das categorias estão sustentadas nos documentos da legislação: Constituição de 1988, a LDB/96, o PNE (2014) e a BNCC (2015), que foram usados nessa análise, e estão disponíveis à consulta, pois suas fontes de dados não estão restritas, o que prova sua natureza e característica da pesquisa documental (MARCONI; LAKATOS, 2003). A análise toma como referência inicial o cenário para o currículo da Educação Básica do país nas origens da BNCC em 2015. Revisitar os documentos históricos, a legislação, ainda em vigência nos permite tensionar, interpretar e refletir para 
compreender o objeto de pesquisa por meio da análise documental, a qual fomentou as discussões da temática proposta.

\section{Década de 90: marco em conquistas das políticas públicas para a EJA}

Após um período de ditadura militar ao se legitimar uma nova Constituição inicia-se no país um ciclo de transformações inéditas na educação, pois desde o período colonial, a educação não teve ênfase como proposta de política pública. Várias tentativas já haviam ocorrido para mudar esse cenário, a saber, o arrojado projeto de educação dos Pioneiros da Educação em 1932.

Entretanto, somente a Constituição de 1988, veio representar e ainda significar a grande mudança legal da política educacional brasileira. Foi a primeira Constituição a dar vez na história para que a educação tornasse efetivamente um direito efetivo do povo brasileiro, de forma que ao Estado caberia garantir, de forma obrigatória, a educação básica. Essa grande conquista indicaria, portanto, a ampliação da oferta ao ensino, o qual exigia a incorporação das modalidades educativas como um processo de inclusão à formação escolarizada de todas as pessoas, crianças, adolescentes, jovens, adultos e idosos.

No ritmo da Constituição de 88, a LDB (n 9394/98) apresentou as diretrizes para a organização da educação brasileira e desde então, legítima a inclusão das modalidades educativas, a destacar a EJA, a qual deixa de ser supletivo e passa a integrar a educação básica e avança nas diretrizes operacionais para esta modalidade. No postulado da década de 90, consolidou-se muitos avanços, que foram favoráveis para que estados e municípios se responsabilizassem e ofertasse a EJA em seus sistemas de educação.

No Art. 208, $\S 1^{\circ}$ da Constituição Brasileira, a educação é tratada como um direito público subjetivo, o que implica a competência de os poderes públicos disponibilizarem os recursos necessários, garantir esse direito e atendendo as subjetividades e adjacências de segmentos e modalidades educativas numa perspectiva de inclusão social. Essas conquistas, asseguradas na Constituição de 1988, promoveram os avanços para que a Década de 90 , colocasse a EJA num lugar de destaque no cenário educativo como inclusão legitimada para essa camada 
da população, no sentido de fazer uma correção histórica, através da garantia de direitos.

As garantias asseguradas nessa década deram uma alavancada para a Educação Básica, em especial, no que se refere a democratização do acesso à escola e o direito à educação, e a partir dela, uma nova trajetória de políticas públicas foram direcionadas para atender demandas históricas como a erradicação do analfabetismo e à expansão da escolaridade entre jovens e adultos no país, como compromisso de uma política de alfabetização que superasse programas pontuais para enfrentamento desses problemas.

Para essa intervenção, o MEC (1989) convocou a Fundação Educar, com uma comissão composta por especialistas e pesquisadores com pesquisas desenvolvidas ou em desenvolvimento no campo da EJA, como responsáveis para coordenar e executar a discussão da política de alfabetização no Brasil, na tarefa de preparar o Ano Internacional da Alfabetização, que foi definido pela UNESCO em 1990.

No Ano Internacional da Alfabetização por todo Brasil foram realizadas diversas discussões e proposições com o debate referente às causas do analfabetismo, direito à educação, políticas públicas para a educação, métodos pedagógicos aplicados à alfabetização, a partir da realização de encontros, congressos e seminários pelas instituições e entidades não governamentais para fomentar e apresentar propostas de enfrentamento sobre o tema. Fruto dessas ações, diversas organizações com notório conhecimento em programas de alfabetização, contribuíram assim com a formatação do Programa Nacional de Alfabetização e Cidadania-PNAC.

Contudo, no que se refere à educação de jovens e adultos, o governo tentou fortalecer uma discussão em torno de um programa de sistema, não apenas de alfabetização, mas de garantia de continuidade na educação básica para jovens e adultos. Para isso, foi criada outra composição na Comissão Nacional com equipe de educadores coordenando os debates sobre a EJA numa perspectiva de Plano Decenal (1993-2003) discutindo paralelamente o Projeto da Nova Lei de Diretrizes e Bases da Educação Nacional (LDB). 


\subsection{EJA: Políticas e resistências}

Em 1994, início do primeiro mandato do governo de Fernando Henrique Cardoso, as Diretrizes para uma Política Nacional de Educação de Jovens e Adultos já estavam construídas, contemplando e contextualizando a situação na qual se encontrava a EJA. Na introdução do documento, o pronunciamento do antigo Ministro da Educação e do Desporto do Governo Itamar Franco, o ex-ministro Murilo de Avellar Hingel, enalteceu e ressaltou sua satisfação com a produção do documento das Diretrizes para educação de jovens e adultos.

[...] documento de diretrizes da Política de Jovens e Adultos, que o Ministério da Educação e do Desporto tem a grata satisfação de editar e divulgar, organizado com a participação da Comissão Nacional de Jovens e Adultos, deverá ser entendido como a manifestação da vontade política do Governo de cumprir o que determina o Artigo 208, caput, inciso I, parágrafo $1^{\circ}$ e $2^{\circ}$, isto é, o dever do Estado com a educação será efetivado mediante a garantia de: I - ensino fundamental, obrigatório e gratuito, inclusive para os que a ele não tiveram acesso na idade própria; $\S 1^{\circ}$ - O acesso ao ensino obrigatório e gratuito é direito público subjetivo; $\S 2^{\circ}$ - O não oferecimento do ensino obrigatório pelo Poder Público, ou sua oferta irregular, importa responsabilidade de autoridade competente'." (HINGEL b, 1994:07).

O documento das Diretrizes manifesta o fortalecimento e vontade política com a EJA, no tocante a sua obrigatoriedade e continuidade na oferta regular. Vale ressaltar, que ainda, expressa o reconhecimento da EJA como fruto das mobilizações sociais pelos setores oficiais e a sociedade civil, que atuavam na Educação de Jovens e Adultos, e que lutaram para garantir a opção da Nacional de Alfabetização e Cidadania (D.O. de 12/09/90, Seção II), como linha de ação para as demandas da EJA.

Com a mudança de governo em 1994, há uma ruptura na proposta para educação, que impôs um caráter de descontinuidade na política educacional brasileira. Assim, todo esforço de mobilização para elaboração da LDB, com participação das representações populares, entidades, pesquisadores e sociedade civil no âmbito regional e estadual a respeito da EJA, foi desconsiderado na promulgação da Lei Darcy Ribeiro, ou seja, Lei de Diretrizes e Bases da Educação Nacional ( $n^{\circ}$ 9394/96). 
[...] ampliar a oferta de educação básica para os jovens e adultos excluídos do sistema regular de ensino, mantê-la enquanto não tiver sido assegurada a todos a efetiva oportunidade de acesso e progressão com sucesso à escola fundamental na idade própria;propor à escola redimensionar o seu atendimento a jovens e adultos, encontrando modos que, sem renunciar à sua função recíproca de preservação, transmissão e produção do conhecimento, possam efetivamente ir ao encontro dos limites impostos pelas condições concretas de vida da população trabalhadora (HINGEL a, 1994, p.18).

Apesar das políticas de descontinuidade, o país nunca avançou tanto em relação a EJA no que se refere ao caráter de reparação social. Porém, quanto a LDB/96, embora esteja com o status de modalidade de Educação, foi reduzida em cursos e exames supletivos, um incentivo aos jovens para abandonarem as classes regulares de ensino. Essa alteração foi considerada como um grande golpe ao texto original das comissões que trabalharam para a elaboração das diretrizes.

Os ranços e avanços, que marcaram a década de 90, principalmente a promulgação da LDB/96, que no artigo 37 apresenta a EJA como resgate e garantia da educação para aqueles e aquelas, que estiveram historicamente na exclusão do processo de escolarização, bem como "A educação de jovens e adultos será destinada àqueles que não tiveram acesso ou oportunidade de estudos no ensino fundamental e médio na idade própria". Esse artigo trouxe o caráter de cumprimento de dívida social e enfatizou o direito à educação por um processo de inclusão não compensatório para a modalidade, consolidou um ganho social sem precedente que exigiu uma reformulação pedagógica tão necessária à EJA.

Por conseguinte, o Parecer CNE/CEB 11/2000 que foi elaborado sob a coordenação do Relator Conselheiro, Carlos Roberto Jamil Cury do Conselho Nacional de Educação-CNE e aprovado em 10 de maio de 2000, em duas partes: I Relatório e voto do relator; II - a Decisão da Câmara, retoma a determinação da LEI 9.394/96, apresentando que a EJA deveria receber um tratamento diferenciado por ser status de modalidade da Educação Básica e possuir uma especificidade própria (BRASIL, 2002b, p. 25-26).

De fato, o Parecer 11/2000 do CNE reconhece a trajetória histórica da educação de jovens e adultos como parte de um plano educacional, a qual valida e 
direciona a política da EJA, quando reafirma, conforme a Constituição brasileira, o direito à educação para homens e mulheres, num princípio de igualdade e de justiça social para os ciclos humanos da juventude e maturidade para atender suas pluralidades e demandas históricas, que desde a colonização do Brasil, permaneciam silenciadas nos documentos oficiais e nas propostas de educação para a nação.

Em vista disso, esta referência do Parecer 11/200 legitimou os avanços legislativos para a política de EJA, ampliando através do documento das Diretrizes Nacionais para a EJA, a formação permanente em continuidade com o tratamento específico dentro da Educação Básica para a modalidade. E ainda, alinhou-se com outros documentos, fruto das conquistas no campo da EJA como o PNE, a partir dos compromissos firmados pelo país na Declaração de Hamburgo, ou seja, na $V$ Conferência Internacional de Jovens e Adultos - CONFINTEA (CUNHA, 1997).

Articuladas ao cenário de reivindicações e aos anseios da sociedade civil, as diretrizes sobre a educação de jovens e adultos, destacou um conceito de educação, próprio às especificidades da EJA,

A necessidade de contínuo desenvolvimento de capacidades e competências para enfrentar essas transformações alterou a concepção tradicional de educação de jovens e adultos, não mais restrita a um período particular da vida ou a uma finalidade circunscrita. Desenvolve-se o conceito de educação ao longo de toda a vida, que há de se iniciar com a alfabetização. Mas não basta ensinar a ler e a escrever. Para inserir a população no exercício pleno da cidadania, melhorar sua qualidade de vida e de fruição do tempo livre, e ampliar suas oportunidades no mercado de trabalho, para que a educação de qualidade se efetive é necessário garantir o atendimento aos princípios da: igualdade de condições para o acesso e permanência na escola; liberdade de aprender, ensinar, pesquisar e divulgar o pensamento, a arte e o saber; pluralismo de ideias e concepções pedagógicas e coexistência de instituições públicas e privadas de ensino [...] (BRASIL, 2000).

O Parecer 11/2000 responde aos anseios das especificidades para a EJA e direciona as políticas públicas de educação para a modalidade no sentido de acatar as expectativas do mundo, pois permanece a função atribuída à EJA, qual seja a de reparação, equalização e qualificação para o mundo do trabalho. Essas funções são trazidas para as estratégias do PNE para atender ao contexto de globalização numa 
sociedade neoliberal. Essa sociedade, ostenta um contexto de exigências de políticas públicas que promovam inclusão no mundo do trabalho, demandas específicas e direcionadas pelo currículo escolar, o que exige da gestão pública investimentos na educação em todas as esferas, ou seja, federal, estadual e municipal, outorgando tais exigências por meio do discurso de desenvolvimento do país.

Conforme a Constituição de 1988, o Plano Nacional de Educação aprovado em 2001 e transformado na Lei $n^{\circ}$ 10.172/2001, determinou grande força para garantia de execução e viabilidade de um plano de compromissos sociais, a serem cumpridos pelo viés da educação. Esse plano retratou um pensamento Freiriano, que realça e expressa as intenções propositivas do PNE em suas metas. "Se a educação sozinha, não transforma a sociedade, sem ela tampouco a sociedade muda" (FREIRE, 2000, p.67).

A construção do PNE tem as marcas da democracia como princípio e prioridade da sociedade civil representada pelas entidades governamentais e não governamentais, no formato de conferências municipais, estaduais e nacional. $O$ PNE trouxe a meta 9 para a modalidade EJA e apresentou estratégias para intervenção na educação no sentido de privilegiar com os objetivos de

[...] priorizar ações de alfabetização, associar o Ensino Fundamental de jovens e de adultos à educação profissional e facilitar parcerias entre o governo e a sociedade civil. Suas metas são que se alcancem em cinco anos, a oferta das quatro primeiras séries iniciais, pelo menos a $50 \%$ da população com 15 anos ou mais, que não tenham concluído a primeira etapa do Ensino Fundamental, além de dobrar, em cinco anos e quadruplicar, em dez a oferta do Ensino Médio (BRASIL, 2001, p. 74-75).

O PNE se estabeleceu como uma lei de compromisso, para dez anos, com planejamentos, investimentos e execuções de metas e estratégias de gestão para a educação do país, e para a modalidade EJA, objetivos sistematizados pelas demandas da sociedade, das quais formaram pauta de reivindicação de outrora, que vem atravessando décadas por uma reforma na educação brasileira.

As metas estabelecidas para o PNE são abrangentes e exigiu das conferências em âmbito municipal e estadual que focassem suas demandas dentro 
dos seus planos a partir da meta. Por essa razão, a educação de jovens e adultos tem sido ofertada sob diferentes formas, resultado da flexibilidade atribuída a essa modalidade por meio de documentos normativos. Essa abrangência da Meta 9 do PNE, exige esforço de gestão no sentido de cumpri-la pelo compromisso com o documento e com a EJA, correndo-se o risco de precedentes e negligências.

No PNE predomina a concepção da EJA como sendo apenas alfabetização em cada uma das etapas do Ensino Fundamental. Uma ideia de correção de fluxo escolar para distorção idade ano. Essa posição colocou a EJA numa condição de suplência como principal função e não assume o que a Modalidade determina na $\mathrm{LDB} / 96$.

O processo de percurso do PNE ainda em andamento, qual ainda não se completou o tempo para atingir a meta $9 \mathrm{com}$ as estratégias definidas para a EJA, vários compromissos assumidos com a modalidade entram em conflito com a lei de compromisso do PNE, com a redução dos investimentos desde 2018 e a negação de ampliação de novos investimentos na educação pelo atual governo representa, reforça ainda mais, a possibilidade de a EJA ficar às margens do caminho.

No final do século $X X$ e início do século $X X I$, o projeto educacional para a modalidade EJA teve como momento épico a década de 90. As conquistas que se iniciaram a partir da Constituição de 1988, na afirmação da educação como direito de todos e dever da sociedade, a qual incluiu os seus sujeitos e garantiu que a pauta da educação para jovens e adultos estivesse presente pelas proposições de reforma da educação, na aprovação da LDB/96, e como modalidade de educação, a ser contemplada com os recursos destinados à educação básica, no entendimento na perspectiva de assegurar a escolarização nesta etapa da educação básica e assim, garantir uma das prerrogativas da $\mathrm{V}$ CONFINTEA, a Educação ao longo da vida.

Quando se destaca a década de 90, como marco para o avanço das políticas públicas para a educação de jovens e adultos, se faz pelas conquistas desse tempo histórico, com tantos significados para a modalidade EJA. A partir dos documentos oficiais, os quais trouxeram as características fundamentais deste segmento, para assegurar o direito à educação daqueles e daquelas que estavam em processo de exclusão no direito de estudar. Nesse contexto temporal, o conceito de educação se 
amplia para uma proposta de educação permanente ao longo de toda a vida, assegurada e financiada por recursos direcionados.

Reafirmar os avanços da década de 90 para a EJA é reconhecer os esforços para uma proposta para a educação de jovens e adultos, que não foi reduzida a um programa de alfabetização. A posição enquanto modalidade da educação básica, conferiu as condições para que os sujeitos históricos da EJA conquistassem o espaço da escola pública e adquirissem possibilidades de exercer sua cidadania com qualidade de vida, como sujeitos de produção de conhecimento representados na sociedade pela escola, assim como, em todos os aspectos vinculados aos direitos humanos e sociais.

\section{Silêncio e negação da EJA no documento da Base Nacional Comum Curricular}

A "década histórica" da EJA também foi atravessada por "ranços" e resquícios das políticas educacionais do passado, sob forte interesse da economia e do setor político com premissas do Banco Mundial para uma educação pública de pouco investimento do Estado, com "[...] sistemas educativos de maior eficácia com o menor impacto possível nos gastos do setor público [...]" (DI PIERRO, 2001, p. 323), ao atribuir e focar os investimentos da educação com vistas à maior taxa de retorno econômico individual e social, centralizando os gastos públicos no Ensino Fundamental regular em detrimento das modalidades de ensino como a educação de jovens e adultos (DI PIERRO, 2001). Nessa direção, a EJA esteve numa condição marginal, quando se fez as reformas daquele período para finalizar o século $X X$.

Nesse confronto das possibilidades, a ameaça da Base Nacional Comum Curricular para com a EJA é real. Segundo Tarlau; Moeller (2020, p. 554) esta política pública tem como orientação um "[...] papel de fundações privadas e corporativas para a formulação e aprovação da BNCC.", que, dessa forma, traz uma outra perspectiva para a educação, a qual diverge nas concepções de educação para a diversidade. É a diversidade que gera a modalidade educativa. 
Tendo em vista que a EJA há uma miscigenação cultural, o currículo terá que articular saberes dos diferentes sujeitos, zelando pela ideia de muitas realidades que precisam ser conhecidas em sala de aula com o cuidado de não reforçar as desigualdades presente na sociedade (MORAES; CUNHA; VOIGT, 2019, p.9).

Quais sujeitos que se insere nesta diversidade? O jovem trabalhador dos canteiros de obra da cidade? Os vendedores e vendedoras ambulantes? As domésticas? Os vigilantes? Os desempregados? Apenados? O jovem e adulto do campo? A modalidade EJA é uma conquista social da sociedade civil que resiste aos desafios impostos pela política educacional neoliberal adotada pelo MEC, com fortes expressões de exclusão social nestes últimos cinco anos, a qual é reafirmada na BNCC com o silêncio revelador da exclusão através da invisibilidade da EJA.

\begin{abstract}
Não poderíamos deixar de tratar aqui sobre a questão da diversidade. O tema da diversidade é um tema posto na nossa sociedade com especial destaque em décadas recentes. Diversidade de gênero, de raça, de território. Diversidade que se converteu em diferenças e em desigualdades. Hoje os movimentos sociais trazem uma marca, a marca de afirmar os coletivos diversos. De defender a diversidade, de não querer anular suas diversidades em políticas de integração, em espaços amorfos, sem rosto, sem cor. A pergunta que teríamos que colocar, que projeto de EJA seria sensível e daria conta desse movimento para reconhecer os diversos? Ou ainda, será que temos um projeto em que o diverso não aparece, em que todos somos iguais, em que todos somos filhos de Deus, todos somos cidadãos, todos somos EJA? Há muita reflexão que poderá fundamentar projetos de EJA que reconheçam, respeitem e incorporem a diversidade sócio educacional de gênero, território dos jovens e adultos populares (ARROYO, 2007, p.12).
\end{abstract}

Reconhecer as especificidades de cada grupo é um fator pedagógico fundante para o bom desempenho dos sujeitos, pois cada etapa do desenvolvimento humano ou mesmo cada situação de aprendizagem, requer técnicas e conhecimentos pedagógicos específicos que possibilitem aos sujeitos uma dimensão pessoal, afetiva, lógico-matemático com o objeto do conhecimento. Neste sentido, uma pedagogia que não atende a diversidade cultural e os desejos de aprendizagem dos jovens e adultos trabalhadores compromete as necessidades/ orientações curriculares, para o público da EJA.

Está muito claro a objetividade do silenciamento da EJA na BNCC, cuja modalidade não foi contemplada com o mesmo respeito e seriedade, assim como a 
educação infantil, anos iniciais e finais do ensino fundamental e ensino médio, negligenciando para os sujeitos da EJA a oportunidade de um diálogo coerente com sua história pessoal, desejos e dificuldades no acesso à escola e sobretudo com o sentido e significado da diversidade para este segmento.

No texto da BNCC, a EJA não apresenta nenhuma diretriz de trabalho para a modalidade, o que representa silenciamento e risco da negação de direito a educação para todos, corroborando assim, no desaparecimento desta modalidade de educação e consequentemente engrossando os dados do analfabetismo no Brasil.

O processo de aprendizagem do indivíduo ao longo da vida, é um fato, o qual é experienciado por todas as pessoas, desta forma, uma opção pedagógica que nega os saberes, os conhecimentos que os sujeitos constroem na convivência familiar, nos grupos sociais e na escola, dentre outros, estará promovendo práticas educativas excludentes, com uma opção política alinhada com regimes autoritaristas que negam as necessidades de métodos e técnicas pedagógicas coerentes com as características de aprendizagem de cada pessoa.

É uma humilhação para um adulto ter que estudar como se fosse uma criança, renunciando a tudo o que a vida lhe ensinou. É preciso respeitar o aluno adulto, utilizando-se uma metodologia apropriada, que resgate a importância da sua biografia, da sua história de vida. Os jovens e adultos alfabetizandos já foram desrespeitados uma vez quando tiveram seu direito à educação negado. Não podem, ao retomar seu processo educacional, serem humilhados, mais uma vez, por uma metodologia que lhes nega o direito de afirmação de sua identidade, de seu saber, de sua cultura (GADOTTI; COUTO, 2018, p.139).

Na segunda metade do século passado, Paulo Freire com uma metodologia coerente com contexto social, realizou provocações com temas geradores e com a apresentação de palavras com forte significado social e com muito respeito à cultura e saberes desses sujeitos, iniciou a alfabetização de pessoas adultas. O diálogo estabelecido por Freire com as pessoas sobre sua cultura, seus saberes, sua história de vida e sobretudo, sobre sua condição/forma de estar no mundo, desencadeou uma lógica de assimilação entre sentido e significado, codificar e decodificar símbolos, permitindo alfabetizar adultos em 40 horas. 
A EJA tende a configurar-se, cada vez mais, como um projeto de educação popular dos jovens e adultos jogados à margem. Daí, podemos tirar uma conclusão: a EJA continua tendo sentido enquanto política afirmativa desse coletivo cada vez mais vulnerável. Não poderá ser diluída em políticas generalistas. Em tempos em que essa configuração dos jovens e adultos populares em vez de se diluir está se demarcando, cada vez com mais força, a EJA tem de assumir-se como uma política afirmativa com uma marca e direção específica (ARROYO, 2007, p. 2).

A oferta da modalidade EJA, no contexto de suas especificidades, permite aos seus sujeitos um diálogo profundo, com as contradições que afetam/negligenciam/confundem/ embaraçam uma leitura de mundo coerente com a lógica social, articulada com outras possibilidades de existência, pois a aquisição da leitura e escrita e a reflexão da realidade objetiva, está ancorada em postulados pedagógicos que vislumbra aos sujeitos da EJA que uma outra sociedade é possível.

\section{Considerações finais}

Não há dúvida sobre as conquistas legais que demarcaram a EJA no cenário da política educacional a partir da constituição de 1988, possibilitando aos seus sujeitos galgarem mais um degrau na inclusão de direitos sociais e políticos. A definição da EJA, na atual LDB/96, como modalidade da educação básica e sua regulamentação com a Diretrizes Curriculares Nacionais para a educação de jovens e adultos (DCN's/EJA), assegurou a inclusão desta modalidade da educação básica, nos debates pedagógicos que envolvem o desenvolvimento do ensino no âmbito do Ministério da Educação e secretarias estaduais e municipais de educação, ampliando os estudos e pesquisas sobre os sujeitos da EJA, dentre outras, no que se refere às características de aprendizagens, saberes provenientes da vida cotidiana, currículo, formação de professores, metodologias e materiais didáticos.

No entanto, o século XXI, representa através da BNCC, a desconsideração de toda trajetória na construção de políticas públicas para seu fortalecimento e consolidação na educação brasileira. A ausência da EJA na BNCC impactou a modalidade, uma vez que, pelo país afora, ela fica à mercê dos critérios de cada 
município e de cada estado para fomentar ou não a continuidade da mesma, pois o caráter da não obrigatoriedade ficou subentendido, ou mesmo, oferecer um currículo que não dialoga com suas especificidades e contextos socioculturais como ensinou Paulo Freire.

Contudo, mais uma vez, um novo tempo de lutas e resistências se anuncia para os sujeitos da EJA, é preciso sustentar conquistas! Mesmo num cenário político brasileiro devastador quanto à violação dos direitos humanos e desenvolvimento social, sem perspectivas para reconhecimentos de políticas públicas que assegurem a caminhada percorrida para a garantia de direitos, é preciso caminhar com a certeza que outro país é possível.

Nessa direção, as reflexões sobre a temática proposta, direcionam para projeção dos contextos futuros, que afetarão a educação de jovens e adultos sem precedentes. Um risco às conquistas firmadas em apenas uma década. Será necessária a retomada de uma luta que sempre se lutou: o direito à educação para aqueles e aquelas que tiveram seus percursos interrompidos ou negados historicamente. A luta está diante de todos/as aqueles/as que militam na EJA e pela EJA.

E vamos à luta, pois as nossas armas são as palavras!

\section{Referências}

ALVES, Nilda. Sobre a Possibilidade e a Necessidade Curricular de uma Base Nacional Comum. Revista e-Curriculum, São Paulo, v. 12, n. 03 p.1512-1529, out./dez. 2014. Disponível em:

https://revistas.pucsp.br/index.php/curriculum/article/view/21664 Acesso em: jun. 2020.

ANPED e ABdC. Exposição de Motivos sobre a Base Nacional Comum Curricular. 2015. Disponível em:

http://www.anped.org.br/sites/default/files/resources/Of_cio_01_2015_CNE_BNCC.p df Acesso em: dez.2015.

ARROYO, Miguel. Balanço da EJA: o que mudou nos modos de vida dos jovens-adultos populares? REVEJ@-Revista de Educação de Jovens e Adultos, 
v.1, n.0, 2007. Disponível em:

http://forumeja.org.br/go/files/Balan\%C3\%A7o\%20da\%20EJA\%20-\%20Arroyo.pdf

BRASIL. Constituição Federal de 1988. República Federativa do Brasil. Brasília: Senado Federal, Centro Gráfico, 1998. Disponível em:

https://presrepublica.jusbrasil.com.br/legislacao/91972/constituicao-da-republica-fede rativa-do-brasil-1988

BRASIL. Lei de Diretrizes e Bases da Educação Nacional, 9.394, de 20 de dezembro de 1996. Disponível em: http://portal.mec.gov.br/arquivos/pdf/lei\%209394.pdf

BRASIL, Ministério da Educação. Portal do MEC. Base Nacional Comum Curricular. Notícias: Coordenadora pedagógica da Base fala sobre o processo de construção do documento. Brasília, 2016.

http://portal.mec.gov.br/component/tags/tag/36402-base-nacional-comum-curricular Disponível em: . Acesso em: mar 2021.

BRASIL, Ministério da Educação (MEC/SEED). Documento preliminar à Base Nacional Comum - Princípios, formas de organização e conteúdo. Brasília, 2015. Disponível em:

http://portal.mec.gov.br/component/tags/tag/36402-base-nacional-comum-curricular Acesso em: março de 2021.

BRASIL, Ministério da Educação (MEC/SEED). Base Nacional Comum Curricular. 2a versão revista. Brasília, 2016. Disponível em.

http://portal.mec.gov.br/component/tags/tag/36402-base-nacional-comum-curricular Acesso em março. 2021.

GADOTTI, Moacir; FEITOSA, Sônia Couto Souza. Reinventar a educação é inverter prioridades: o lugar da educação de adultos como política pública. In: ; CARNOY, Martin. Reinventando Paulo Freire: a práxis do Instituto Paulo Freire. São Paulo: Instituto Paulo Freire. Lemann Center/ Stanford Graduate School of Education, 2018.

GIL, A. Carlos. Métodos e Técnicas de Pesquisa Social. 5. Ed. São Paulo: Atlas, 2006.

MARCONI, M. de Andrade. LAKATOS, E. Maria. Fundamentos de metodologia científica. 5. Ed. São Paulo: Atlas, 2003.

MEC. Parecer CNE/CEB no 11/2000 de 9 de junho de 2000. Acesso em 08 de julho de 2015. Disponível em

http://portal.mec.gov.br/secad/arquivos/pdf/eja/legislacao/parecer_11_2000.pdf Acesso em: dez. 2015.

MORAES, Marilei Schackow; CUNHA, Silmara dos Santos da; VOIGT, Jane Mery Richter. Onde está a Educação de Jovens e Adultos na BNCC? V COLBEDUCA - Colóquio Luso-Brasileiro de Educação 29 e 30 de outubro de 2019, Joinville/SC, Brasil. Disponível em: https://www.revistas.udesc.br/index.php/colbeduca/article/view/17236 Acesso em março de 2021.

Revista de Políticas Públicas e Gestão Educacional (POLIGES) - UESB-Itapetinga. ISSN: 2763-5716 Ano 2021, vol. 2, n. 1, set. - dez. de 2021. 
TARLAU, Rebecca; MOELLER, Kathryn. O consenso por filotropia: como uma fundação privada estabeleceu a BNCC no Brasil. Currículo sem fronteiras, v. 20, n.2, p. 553-603, maio/ago. 2020 Disponível em:

http://curriculosemfronteiras.org/vol20iss2articles/tarlau-moeller.pdf Acesso em março de 2021.

\section{SOBRE AS AUTORAS}

\section{Daniela Lopes Oliveira Dourado}

Mestre em Educação de Jovens e Adultos - UNEB; Docente do Curso de Pedagogia do DCHT Campus XVI/ UNEB Brasil; Membro do Grupo de Pesquisa CONPEEJA-UNEB/ CNPq. Correio eletrônico: dannylopes11@gmail.com

\section{Ana Karine Loula Torres Rocha}

Doutora em Educação e Contemporaneidade - UNEB; Docente do Curso de Pedagogia e Coordenadora do Curso de Administração da UNEB DCHT Campus XVI - Irecê - Brasil. Membro do Grupo de Pesquisa em Trabalho, Educação, Gestão e Tecnologias GENTTES-UNEB/ CNPq. Correio eletrônico: aklrocha@uneb.br

\section{Cinara Barbosa de Oliveira Morais}

Mestre em Educação de Jovens e Adultos - UNEB; Docente do Curso de Pedagogia da UNEB DCHT Campus XVI - Irecê - Brasil; Membro do Grupo de Pesquisa Conjunturas de Pesquisas e Estudos em Educação de Jovens e Adultos - CONPEEJA- UNEB/ CNPq. Correio eletrônico: cinarabarbosaom@hotmail.com

\section{Maria de Fátima Sudré Andrade}

Mestre em Educação de Jovens e Adultos - UNEB; Docente do Curso de Pedagogia da UNEB DCHT Campus XVI - Irecê - Brasil; Membro do Grupo de Pesquisa Conjunturas de Pesquisas e Estudos em Educação de Jovens e Adultos - CONPEEJA- UNEB/ CNPq. Correio eletrônico: fatima.sudre@hotmail.com 